11. Launois et Mulon.-Comp.rend.de l'Assoc.des Anatomistes. Liège, 1903.

12. Mayer.-Arch.f. Gyn., Vol. XC, 1910.

13. Gentili.-Arch. d. Biol., 1920.

14. Fisher.-Proc. of the Roy. Soc. Med., Vol. VI, p. 54.

15. Beckerhaus.-Schwangerschaftshyperplasie der Hypophyse und Gesichtsfeld. Arch. f. Augenheilk., 1925.

16. Erdheim and Stumme. - Schwangerschaftsveränderung. Beiträge zur Path. Anat. und zur allgemeinen Pathologie. Ziegler's Beiträge, Bd. XLVI, 1909.

17. Finlay. - Bitemporal contraction of the vision fields in pregnancy. Proc. Internat. Cong. of Ophthal., Washington, 1922.

18. Carvill.-Proc. Internat. Cong. of Ophthal., p. 154, Washington, 1922.

19. Fewell.-Trans. Ophthal. Soc. U.K., Vol. XLIII, p. 60.

20. Lohlein.-Die bitemporale, Hemianopie der Schwangeren. Monatschr.f. Geb. u. Gyn. Bd. LXV, H. 3-4.

21. Igersheimer.-Ein neuer Weg zur Erkenntnisskrankhafter Vorgange in der Sehbahn. Bericht, S. 352, 1916. Heidelberg.

22. Bellinzona and Tridonani.-Boll.d'Soc. med.-chir. di Pavia, 1903.

23. Forti.-Arch. di Ottal., February, 1910.

24. Traquair.-Proc. of the Roy. Soc. Med., p. 99, April, 1926.

25. Fisher.-Brit. Jl. of Ophthal., October, 1917.

26. Holn.-Gesichtsfeldeinschrankung während der Gravidität. Zentralb.f. Gynäkol., Bd. XXXVII, 1924.

27. Schoninger.-Das Gesichtsfeld in der Schwangerschaft. Klin. Monatsbl. f. Augenheilk., Bd. LXXII, 1924.

28. Parsons.-Diseases of the Eye. P. 374, 1923.

29. Harman, Bishop.-Proc. of the Roy. Soc. Med., Vol. VI, p. 11, 1913.

\title{
UNILATERAL CHRONIC ANTERIOR UVEITIS IN CHILDREN. A CLINICAL NOTE
}

By

\section{ERNEST THOMSON}

STIRLING

From the standpoint of clinical observation and research the post of oculist to a large education authority has certain advantages and certain drawbacks. The principal advantage is that one sees a large number of young people who may show the beginnings of disease which otherwise might go unnoticed. Parents will bring a child when they have been definitely notified by the School Inspection Staff that the eyesight of the child is defective, although of their own initiative they would not seek advice: such failure to seek advice is either because they are unaware of the defect or do not think it important. The principal drawbacks are two in number. The first is that while one may see the beginnings of disease there is usually no opportunity to see the end, since the child may and probably will be lost sight of on. 
leaving school. The second drawback is that, at any rate in the case of a county authority, laboratory assistance may not readily be available. In my own case, it happens that as an oculist to the Lanarkshire Education Authority the children may live at any distance between ten and forty or so miles from a first-class clinical laboratory.

It is with great diffidence that the following notes are published, since, though the facts are interesting so far as they go, they do not go very far. For myself, they are unexplained. Worse still, they may be commonplace. Thinking that the latter might be the case I brought the observed facts before the notice of the Scottish Ophthalmological Club a year or two ago and was rather surprised to find that, while many had seen uveitis of one kind or another in children, no one seemed to have specially observed the peculiarity of unilaterality which is the most outstanding feature of the cases here to be described. Since then further cases having come into the list, which now contains ten. I think it my duty to put them forward in order that, if it should turn out that the type is unfamiliar, investigations may. be carried out by those who are in a position really to investigate the aetiology, without a knowledge of which one simply works in the dark. Some of my former colleagues at the Glasgow Eye Infirmary have seen some of the children, notably Dr. Leslie Buchanan and the late Dr. Hislop Manson. Buchanan originally applied the name "chronic anterior choroiditis," but I think "uveitis" leaves the diagnosis more general. Neither of these was able to offer a firm basis of aetiology. Manson, indeed, had undertaken to investigate the cases biologically as they occurred, but, owing to his untimely death, nothing much ever came of it. That he did obtain negative reactions in several I know, but in only one case have I any statement in writing, and in that the syphilis and tubercle reactions were negative. In a letter dated November 29, 1924, he says : "I have never found any determining cause in any of these cases of anterior choroiditis nor have I ever seen any in my clinic" (i.e., other than those I sent him.-E.T.). Again, regarding Mary McD., he wrote on December 4, 1924: "She was in the Infirmary for a week. The Wassermann reaction was negative, von Pirquet was negative, and the general condition showed nothing in particular." She was seen by Dr. Gavin Young who reported "tonsils and adenoids." Manson in this same letter, which was written from his house, stated that this child had keratitis punctata and vitreous opacities in the other eye also, but I am almost certain that this is a fault of memory for I never could find any such signs in it. From my own observation I can say that none of the cases presented any obvious clinical signs of syphilis or tubercle, so that the evidence, so far as it goes, is against these as aetiological 
factors. But it does not go far enough. Concerning aetiology, or rather of the want of it, that is about all I have to tell. The rest refers to clinical signs and symptoms.

The initial characteristics of all ten cases are : (1) Signs of uveal tract disturbance, but without either visible fundus changes or definite iritis. All the pupils dilated readily with atropine though there is evidence in some that the iris was not entirely unaffected. Nor can one be quite definite about fundus changes where there are opacities in the media. All that can be said is that practically there were none when the children were first seen : and, indeed, the only case in which fundus changes were afterwards seen was that of William G., who developed detachment of the retina and possibly of the choroid. (2) Unilaterality of the trouble, the other eye being either completely normal or presenting changes having no obvious connection with those in the affected eye. The case of Mary McD. is, it is true, a possible exception but for the reason stated above I do not think so. (3) Great chronicity. Only one appeared to be cured, at any rate in so far as visual acuity was $6 / 6$ when seen two years later; but there were still some vitreous opacities-this case was Mary McL. On the other hand, Annie Y. seemed to be cured and obtained vision $=6 / 6$, but had a slight relapse after four years from the date when first seen.

The above-mentioned signs of uveal tract disturbance consisted in all the cases in vitreous opacities, sometimes fine and dust-like. sometimes coarser and floating, while sometimes there were both types. In four cases there were posterior corneal deposits. In one of these, the one that appeared to be cured fairly definitely, they disappeared. In one they were only noted for the first time after the child had been under observation for a year, while in the remaining two cases they were still present respectively four and three years afterwards. The progress of one case was very exceptional, namely William G. This boy was first seen when he was thirteen on June 2, 1920. At that time there was nothing wrong beyond an error of refraction, the visual acuity being $5 / 6$ in either eye with correction. On April 30, 1923, he was put forward to me because of serious lowering of the vision of the right eye to 6/60. He was then classed as a typical case of unilateral chronic anterior choroiditis, the acuity of the left eye being $6 / 6$ at which it remained until last seen in May, 1926. He was referred to Dr. Manson for investigation. I have no note from Manson at this time. Between 1923 and 1924 I discovered that the retina was detached in the affected eye, presenting a festoon-like appearance upwards and inwards. I again sent the boy to Manson when it turned out that he (Manson) had already observed the detachment but had failed to communicate with me. On June 12,1924 , he wrote to the School Medical Officer as follows: "I am familiar 
with the condition of this boy's right eye as noted in Dr. Thomson's letter to you. I had him under my care in the Glasgow Eye Infirmary searching for the aetiology of this separation of the retina and could fine none. I have also a note of the vision of his remaining eye and find that there has been no deterioration in it." Again on November 29, 1924, he wrote to me: "The detachment in William G. is very interesting. It started well forward and up and in. It was very difficult to see at first. Now it is almost complete." Finally, I saw the boy on May 20, 1926, when I noted that the lens was becoming cataractous and that it was difficult to determine the conditions behind it. The retina was apparently almost completely detached and the detachment appeared to me to be red in colour. The acuity of the fellow eye remained $6 / 6$. It is right to say that the question of removing the affected eye was considered but this was not undertaken. Transillumination was reported by Dr. Manson to be negative. The boy has, of course, now left school, indeed had passed out of my care when last seen, and at the moment there is no information available. Should any further history be obtained it will be reported in this journal.

All the material facts so far as they are known about these cases are embodied in the accompanying tabular statement. The treatment ordered, though not always carried out by the parents, was on general principles; cod-liver oil, grey powder, syrup of iodide of iron being the principal standbys. I cannot but emphasize that where these cases have been followed over a period of years an actual cure can hardly be said to have occurred; so that one is inclined to suspect that if they could be followed out to the end that end might be, as in the case of William G., detachment of the retina or some form of disorganization of the affected eye. Indeed, at one of the meetings of the Ophthalmological Club previously referred to, Traquair of Edinburgh had some views which tended in this direction. We should endeavour to determine whether any definite form of adult eye disease corresponds with these juvenile commencements, the end results of which can hardly -in existing circumstances-be seen by the school oculist, who, on the other hand, is much the most likely person to see the early stages. It is very important that, if similar cases come to the notice of the ophthalmic surgeon who is in a position to have them investigated, such investigation should be fully carried out if at all possible.

Obviously, if one definite cause were found, which is perhaps unlikely, we should be in a position to carry out a specific line of treatment which might avert the misfortune of such chronic, and indeed hopeless, deterioration as occurred in the case of William G., or, not to be too pessimistic, such chronic weakness of the affected eye as appeared to be the lot of Annie Y. 


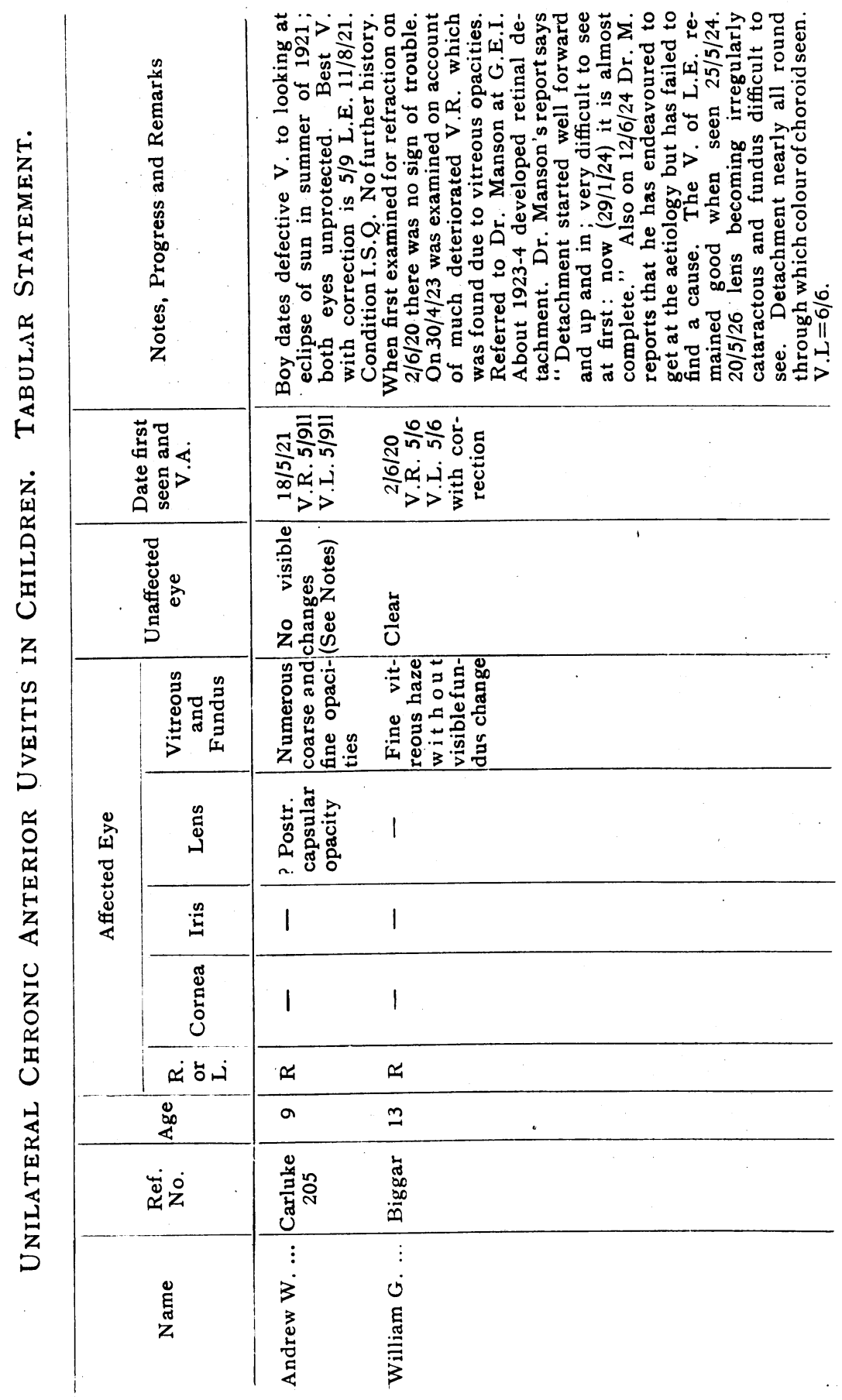




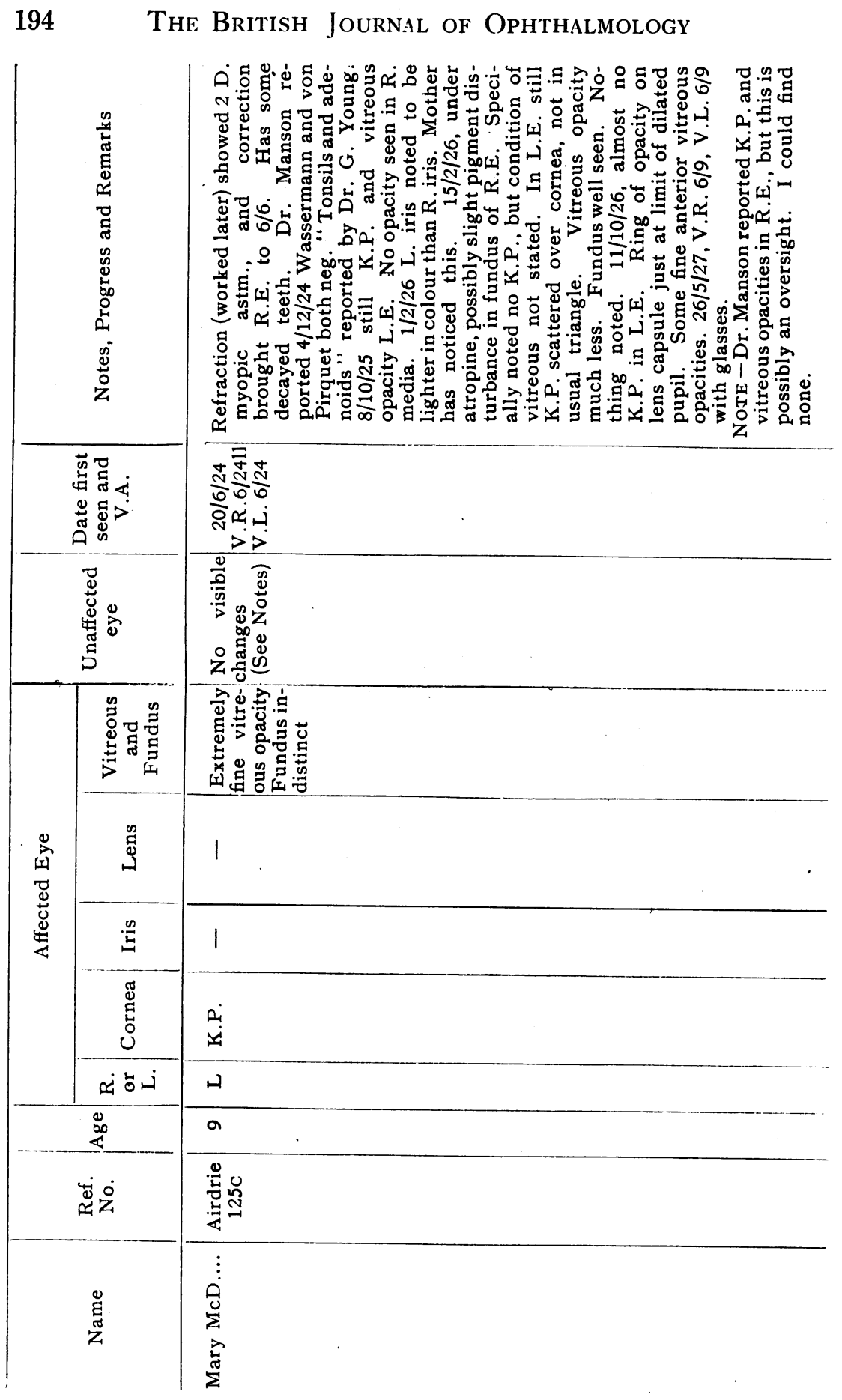




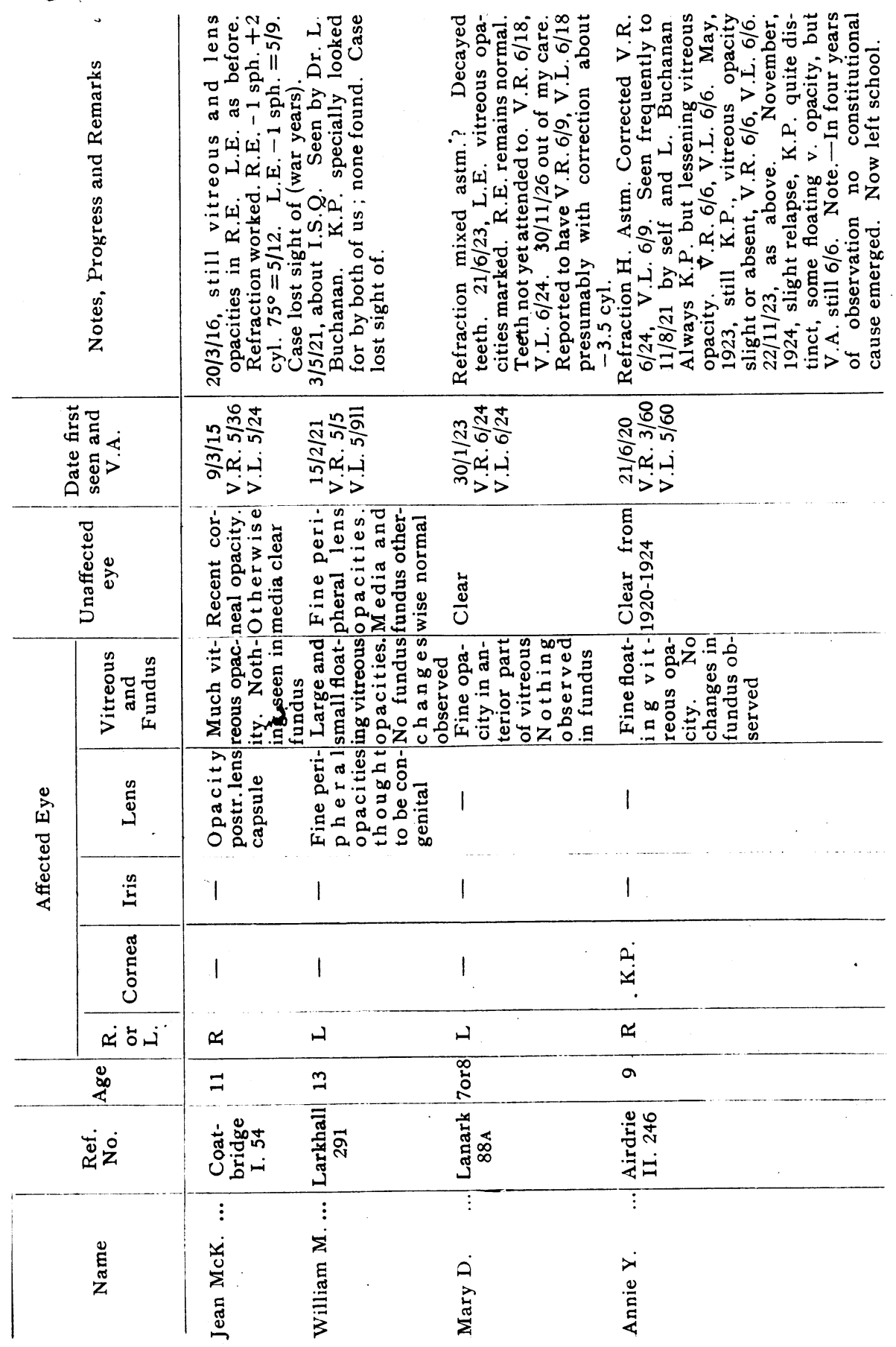




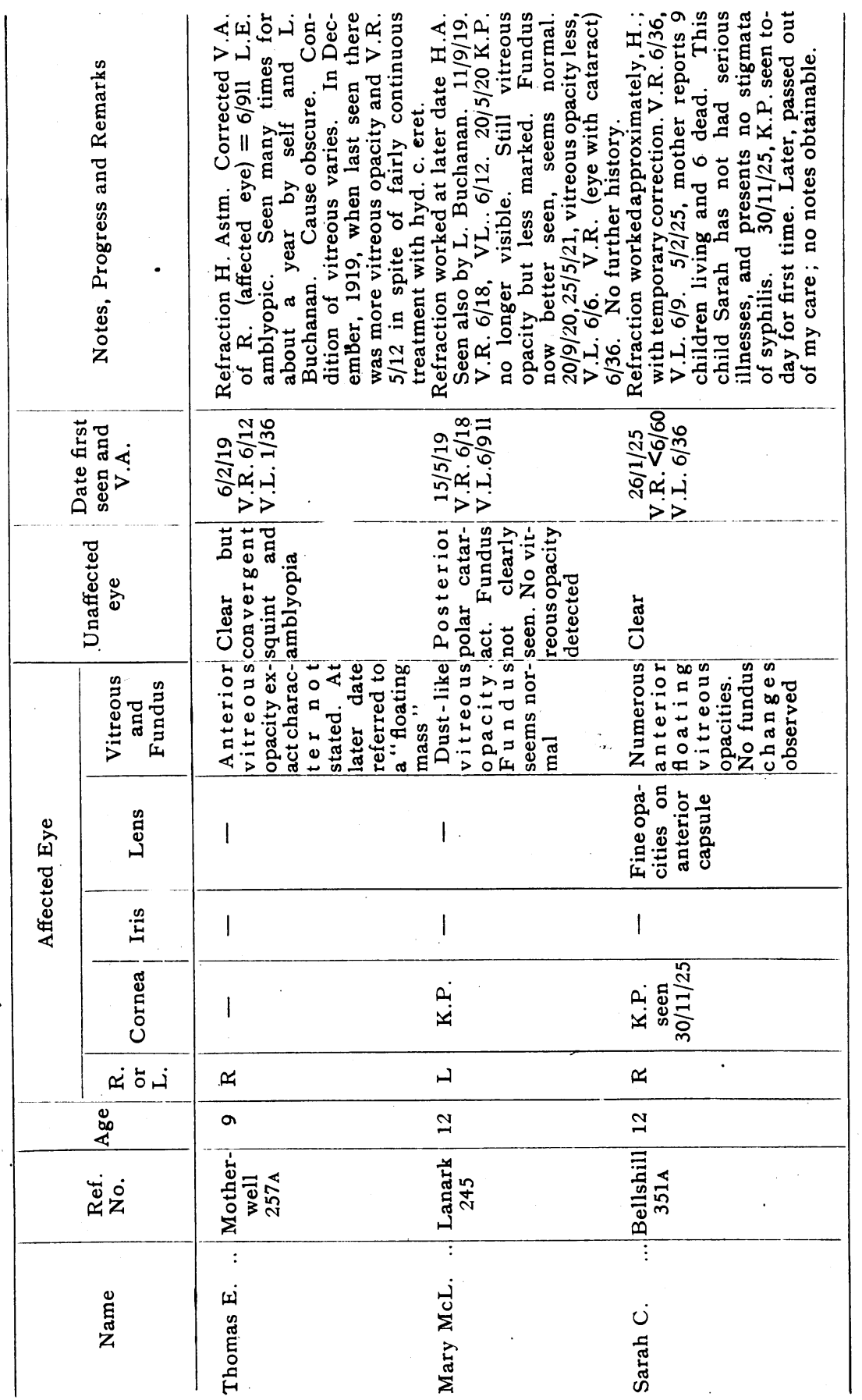

